\title{
Thesis
}

\section{Association of migraine and stress on academic performance (Abstract)}

\author{
Associação da migrânea e estresse na performance acadêmica (Resumo)
}

\section{Francimar Nipo Bezerra}

Thesis (Doctorate in Neurosciences). Postgraduation in Neuropsychiatry and Behavioral Sciences. Federal University of Pernambuco, Recife, Brazil. 2018. 147 f. Supervisor: Prof. Dr. Marcelo Moraes Valença.

$\bigotimes_{\text {fran.nipo@gmail.com }}$

\section{Introduction}

A survey conducted in Brazil among university students from different courses in the city of Ribeirão Preto/SP estimated that among migraine sufferers, school performance was lower than among those who suffered tension-type headache. Issues related to academic life are recognized as triggering factors for high levels of stress and migraine, which generate a reduction in school performance and change in the quality of life of students.

\section{Aims}

General: Analyze the association between migraine and failure stress among college students. Specific: Describe the socio-demographic and academic characteristics of university students; estimate the prevalence of migraine among university students; assess stressors and stress intensity among university students; correlate the occurrence of migraine with the stressors; analyze the occurrence of migraine and non-migrainous headache with the intensity of stress; correlate the occurrence of failure with migraine and non-migrainous headache; analyze the occurrence of failure with the intensity of stress; correlate the occurrence of failure with the stressors.

\section{Method}

Cross-sectional study developed at the Department of Nursing at UFPE. The sample consisted of 197 students with the inclusion criteria: over 18 years of age, attending the second to tenth period of graduation, and regularly enrolled. The collection period was from March 2015 to August 2017. The collection instruments used were: sample and headache characterization, Headache Impact Test and the Instrument for Stress Assessment in Nursing Students. The analysis of stress was carried out by crossing the stress factors mentioned by the study participants and evaluating the intensity of stress, while the assessment of migraine took place through the occurrence of migraine, likely migraine. Academic performance was assessed by students' presence or absence of disapproval. Research approved by opinion number 947615.

\section{Results}

Most participants, $95.9 \%$, suffered from headache, of these $32.5 \%$ had migraine. The most cited stressors at graduation were: full-time workload, $40.3 \%$; tests and works, 38.2\%; time management, $30.9 \%$; content and activity overload, 30.9\%. It was found that in all stress domains, the highest percentage was classified as having low-stress intensity. Regarding the crossings, it was observed that there was a significant association between the occurrence of failure in high-impact migrants (severe HIT), the association between the occurrence of failure and stress intensity was significant and there was a significant relationship between the classification of HIT 6 and the intensity of stress.

Keywords:

Psychological Stress Migraine Disorders Low school performance

\section{Conclusion}

A healthy lifestyle can help reduce stress and migraine levels, and consequently improve academic performance. 